\title{
LETTERS
}

\section{Red hot foot ... keep Charcot arthropathy in mind}

This is in response to a recent practice aticle in CMAJ. ${ }^{1}$ Although infection and gout are likely diagnoses in this presentation, Charcot arthropathy needs to be high up on the differential diagnosis list - particularly when a patient has diabetes. ${ }^{1}$ The presence of pain is not sufficient to rule out this rapidly deforming disease, and early imaging may not detect the developing process. Prompt intervention (nonweight bearing) can prevent life-altering disfigurement. As a podiatrist, I often see patients with Charcot arthropathy only after the foot has collapsed - early foot protection could have protected their mobility.

\section{Adam Zanbilowicz DPM MSc}

Podiatrist, Brickyard Medical Clinic, Nanaimo, BC

Cite as: CMAJ 2017 April 24;189:E612.

doi: $10.1503 / \mathrm{cmaj} .732939$

\section{Reference}

1. Farris GR, Steinhilber S. An older patient with diabetes and severe foot pain. CMAJ 2017;189: E73-5.

Competing interests: None declared. 